Check for updates

Cite this: RSC Adv., 2018, 8, 25456

Received 12th June 2018 Accepted 10th July 2018

DOI: 10.1039/c8ra05042b

rsc.li/rsc-advances

\section{Dynamics revelation of conformational changes and binding modes of heat shock protein 90 induced by inhibitor associations $\uparrow$}

\author{
Jianzhong Chen, (D) *ab Jinan Wang, (D) ${ }^{\mathrm{b}}$ Fengbo Lai, ${ }^{\mathrm{a}}$ Wei Wang, ${ }^{\mathrm{a}}$ Laixue Pang ${ }^{\star a}$ \\ and Weiliang Zhu*b
}

\begin{abstract}
Heat shock protein 90 (Hsp90) has been an attractive target of potential drug design for antitumor treatment. The current work integrates molecular dynamics (MD) simulations, calculations of binding free energy, and principal component (PC) analysis with scanning of inhibitor-residue interaction to probe the binding modes of inhibitors YK9, YKJ and YKI to Hsp90 and identify the hot spot of the inhibitorHsp90 binding. The results suggest that the introductions of two groups G1 and G2 into YKJ and YKI strengthen the binding ability of $\mathrm{YKJ}$ and $\mathrm{YKI}$ to Hsp90 compared to YK9. PC analysis based MD trajectories prove that inhibitor bindings exert significant effects on the conformational changes, internal dynamics and motion modes of Hsp90, especially for the helix $\alpha 2$ and the loops L1 and L2. The calculations of residue-based free energy decomposition and scanning of the inhibitor-Hsp90 interaction suggest that six residues L107, G108, F138, Y139, W162 and F170 construct the common hot spot of the inhibitor-residue interactions. Moreover the substitutions of the groups G1 and G2 in YKJ and $\mathrm{YKI}$ lead to two additional hydrogen bonding interactions and multiple hydrophobic interactions for bindings of $\mathrm{YKJ}$ and $\mathrm{YKI}$ to Hsp90. This work is also expected to contribute theoretical hints for the design of potent inhibitors toward Hsp90.
\end{abstract}

\section{Introduction}

Heat shock protein 90 (Hsp90), a main member of the heat shock protein family, is richly expressed in organisms ranging from bacteria to humans. Hsp90 is an ATPdependent molecular chaperone and plays important roles in maintaining conformation, stability and function of extensive signaling proteins acting as pathways of cell proliferation, cell cycle progression, angiogenesis, invasion and metastasis. ${ }^{\mathbf{1}, 2}$ The previous studies proved that many client proteins of Hsp90 are involved in multiple key oncogenic proteins, such as Her2, AKT, CDK4, VEGF, MET and ALK. ${ }^{3-7}$ Moreover, Hsp90's broad client proteins are known disease-related peptides and implicate the chaperone in the progression of several pathologies relating with various protein misfolding disorders, cancer, and neurological diseases. ${ }^{8-10}$ Thus, Hsp90 has been an attractive target of potential drug design for antitumor treatment.

${ }^{a}$ School of Science, Shandong Jiaotong University, Jinan, 250014, China. E-mail: chenjianzhong1970@163.com; jzchen@sdjtu.edu.cn; lxpang@sdjtu.edu.cn

${ }^{b}$ Drug Discovery and Design Center, CAS Key Laboratory of Receptor Research, Shanghai Institute of Materia Medica, Chinese Academy of Sciences, 555 Zuchongzhi Road, Shanghai, 201203, China. E-mail: wlzhu@simm.ac.cn

$\dagger$ Electronic supplementary information (ESI) available. See DOI: $10.1039 / \mathrm{c} 8 \mathrm{ra} 05042 \mathrm{~b}$
According to the previous studies, inhibitors of Hsp90 can produce simultaneous effects on several abnormal signaling pathways in tumor cells, which may conquer different issues related to cancer resistance. ${ }^{\mathbf{1 1 - 1 4}}$ Since the first Hsp90 inhibitor (17-AAG, tanespimycin) was identified, ${ }^{15}$ extensive efforts have been paid in rational drug design and drug discovery targeting Hsp90. For example, Biamonte et al. applied the structure-based drug design technology to develop the first totally synthesized Hsp90 inhibitor PU3 (ref. 16 and 17) and the following inhibitors CNF-2024 and BIIB021 entering clinical trials in 2005 were also developed based on the pharmacophore model derived from PU3. ${ }^{18,19}$ Yi et al. employed MD simulations and binding free energy calculations to probe binding modes of pyrazolebased inhibitors to Hsp90 and their results revealed that van der Waals interaction is primarily responsible for binding of inhibitors to Hsp90. ${ }^{20}$ Recently, some different inhibitors have also entered clinical trials and displayed certain efficiency in inhibiting the activity of Hsp90. ${ }^{21-27}$ In despite of high efficiency of these inhibitors targeting the N-terminal ATP pocket of Hsp90 in clinical trials, side effects were commonly observed in Hsp90 inhibitors, which heavily limits the clinical studies of some novel inhibitors. ${ }^{28-31}$ Thus it is of significance to further probe binding modes of inhibitors to Hsp90 at atomic level for design of potent inhibitors targeting Hsp90.

It is well known that efficient Hsp90 chaperone cycles depend on extremely flexible structure of Hsp90, which is in 

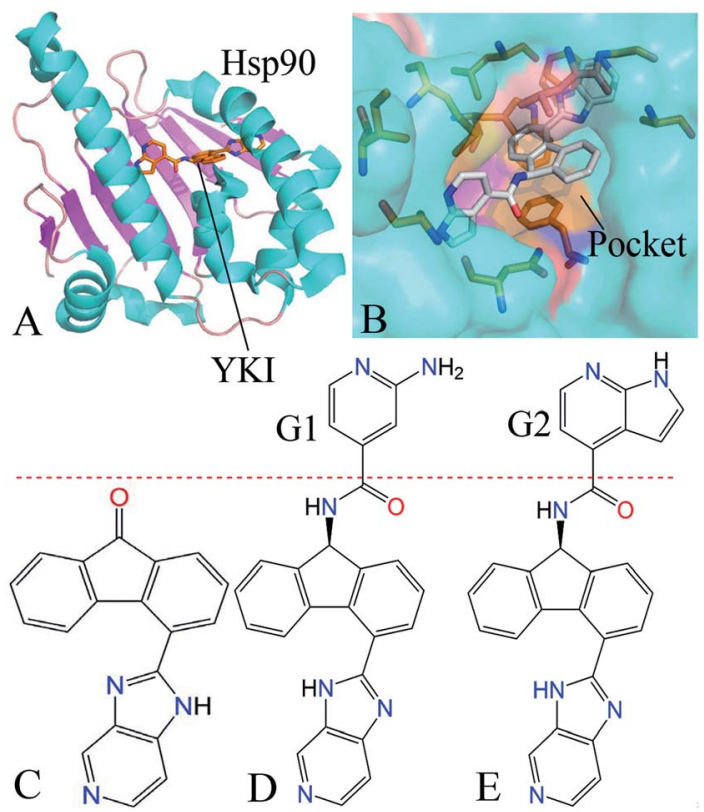

Fig. 1 Molecular structures. (A) The YKI-Hsp90 complex is shown in cartoon modes, (B) binding pocket of $\mathrm{YKI}$ to Hsp90 is displayed in surface modes and the key residues around the pocket are shown in stick modes. (C), (D) and (E) are the structures of inhibitors YK9, YKJ and YKI.

concert with cochaperones and adaptor proteins. ${ }^{32}$ The previous work demonstrated that conformational changes of the $\mathrm{N}$ terminal ATP site of Hsp90 play key role in inhibition of ATP hydrolysis and client processing. ${ }^{33-35}$ In fact, bindings of substrates and inhibitors really induce large-scale conformational changes of Hsp90. ${ }^{8,36-38}$ Moreover, probing drug-protein binding mechanisms and their thermodynamics and kinetics of conformational changes are prerequisites to develop efficient drugs toward targeting proteins. ${ }^{39}$ Therefore, it is essential to explore the conformational changes of $\mathrm{Hsp} 90$ induced by inhibitor bindings for design of potent inhibitor targeting Hsp90.

Recently, MD simulations ${ }^{40-48}$ and principal component (PC) analysis ${ }^{49-53}$ have been powerful tools to study the conformational changes of proteins. Binding free energy calculations ${ }^{54-60}$ were also an important approach to reveal binding modes of inhibitors to proteins. Moreover, the works from Colombo et al. proved that MD simulations have been successfully used to study binding modes of inhibitors to Hsp90 and revealed multiple binding poses in the binding pocket of Hsp90. ${ }^{61-63}$ In this work, we selected three inhibitors YK9, YKJ and YKI to probe binding mechanisms of inhibitors to Hsp90. The structure of inhibitor-Hsp90 complex and binding pocket are depicted in Fig. 1A and B, while the structures of three inhibitors were displayed in Fig. 1C-E. The cause why we selected these inhibitors is because they have different binding ability to Hsp90 and the IC50 values of YK9, YKJ and YKI are 8100, 610 and $30 \mathrm{nM}$, respectively. ${ }^{64}$ We expect that three aims can be realized through this work: (1) MD simulations followed by PC analysis were performed to probe the conformational changes of Hsp90 induced by inhibitor bindings, (2) binding free energies were calculated by using molecular mechanics Poisson-Boltzmann surface area (MM-PBSA) and molecular mechanics generalized Born surface area (MM-GBSA) ${ }^{65-71}$ to comparatively evaluate the binding modes of inhibitors to Hsp90, (3) decomposition of residue-based free energies and scanning of inhibitor-residue interactions were carried out to reveal the hot spot of interactions of inhibitors with Hsp90. This study was also expected to theoretically contribute significant dynamics information and molecular basis to design of efficient inhibitors targeting Hsp90.

\section{Methods}

\subsection{Construction of initial systems}

The initial coordination used in MD simulations were taken from protein data bank (PDB): $2 \mathrm{YK} 9,2 \mathrm{YKJ}$ and $2 \mathrm{YKI}$ separately correspond to the YK9-, YKJ- and YKI-Hsp90 complexes. ${ }^{64}$ The apo Hsp90 was generated by removing YK9 from 2YK9. The protonated state of residues in Hsp90 were checked by using the program PROPKA. ${ }^{72,73}$ All crystal water molecules were kept in the initial model and all missing hydrogen atoms were connected with heavy atoms by using the Leap module in Amber 16. ${ }^{74}$ The parameters of Hsp90 were generated with ff14SB force field of Amber ${ }^{75}$ and that of water molecules were assigned using the TIP3P model. ${ }^{76}$ Molecular structure of three inhibitors were optimized using the Gaussian 09 program at the HF/6$31 \mathrm{G}^{*}$ level, and then restrained electrostatic potential (RESP) charges were assigned to atoms of inhibitors. ${ }^{77}$ Meanwhile, the general Amber force field (GAFF) were applied to produce the force field parameters of three inhibitors. ${ }^{78}$ Each complex was placed in a truncated octahedral box of TIP3P water molecules, extending at least $12.0 \AA$ along each dimension from each complex. The total of seven counterions $\mathrm{Na}^{+}$were added to neutralize each system.

\subsection{MD simulations in waters}

To relieve high-energy contacts between atoms and highly repulsive orientations of protein-solvent system, each system were minimized by the steepest descent minimization of 2000 steps followed by the conjugate gradient minimization of 3000 steps. Then, a gentle heating process of $1 \mathrm{~ns}$ were performed to heat each system from 0 to $300 \mathrm{~K}$ at constant volume and another $1 \mathrm{~ns}$ process of temperature equilibrium at $300 \mathrm{~K}$ was adopted to further equilibrate the simulated system. Finally, a $200 \mathrm{~ns}$ MD simulation without restriction was conducted to fully relax each system and the coordinates of atoms were recorded by at a time intervals of 4 ps. During MD simulations, the SHAKE algorithm ${ }^{79}$ was employed to constrain the chemical bond involving hydrogen atoms so that a time step of $2 \mathrm{fs}$ was adopted. The temperature of systems was controlled by the Langevin thermostat ${ }^{80}$ with a collision frequency of $2.0 \mathrm{ps}^{-1}$. The long-range electrostatic interactions were computed by using the particle mesh Ewald (PME) method with an appropriate cut-off value of $10 \AA$. The same cutoff as calculations of the electrostatic interaction was adopted to calculate van der Waals interactions. PC analysis was performed on MD 
trajectories using the program CPPTRAJ in Amber ${ }^{81}$ and the details concerning PC analysis have been described in our previous studies. ${ }^{50,82}$ The software PyMOL ${ }^{83}$ and $\mathrm{VMD}^{\mathbf{8 4}}$ were applied to analyze MD trajectories and depict pictures.

\subsection{Calculations of binding free energies}

Binding free energies between inhibitors and Hsp90 were calculated by using MM-PBSA and MM-GBSA methods to comparatively evaluate binding ability of inhibitors to Hsp90. The total of 200 snapshots extracted from the last $100 \mathrm{~ns}$ of MD trajectories at a time interval of 500 ps were used to perform calculations of binding free energies based on the following equation.

$$
\begin{aligned}
\Delta G_{\mathrm{bind}} & =G_{\mathrm{comp}}-G_{\mathrm{pro}}-G_{\text {lig }}=\Delta E_{\mathrm{ele}} \\
& +\Delta E_{\mathrm{vdW}}+\Delta G_{\mathrm{pol}}+\Delta G_{\text {nonpol }}-T \Delta S
\end{aligned}
$$

in which $G_{\text {comp }}, G_{\text {pro }}$ and $G_{\text {lig }}$ indicate free energies of the complex, protein and inhibitor, respectively. $\Delta E_{\text {ele }}$ and $\Delta E_{\mathrm{vdW}}$ represent electrostatic and van der Waals interactions of inhibitors with proteins, independently. $\Delta G_{\mathrm{pol}}$ and $\Delta G_{\text {nonpol }}$ are the polar and nonpolar solvation free energies, respectively. In the current work, $\Delta G_{\mathrm{pol}}$ can be separately solved by using the PB and GB model developed by Onufriev et al. ${ }^{85}$ and $\Delta G_{\text {nonpol }}$ is determined by the following empirical equation:

$$
\Delta G_{\text {nonpol }}=\gamma \times \Delta \mathrm{SASA}+\beta
$$

where the parameter $\gamma$ and $\Delta$ SASA separately represent the surface tension and the difference in the solvent accessible surface areas induced by inhibitor bindings. The parameter $\beta$ indicates a regression offset of the linear relationship. In the PB calculations, $\gamma$ and $\beta$ were respectively set to $0.00542 \mathrm{kcal}-$ mol $\AA^{-2}$ and $0.92 \mathrm{kcal} \mathrm{mol}^{-1}$, while in the GB calculations, $\gamma$ and $\beta$ were set to $0.0072 \mathrm{kcal} \mathrm{mol} \AA^{-2}$ and $0 \mathrm{kcal} \mathrm{mol}^{-1}$, separately. ${ }^{86}$ The last term $-T \Delta S$ indicates the contributions of the entropy changes to inhibitor bindings, which is calculated by using the mmpbsa_py_nabnmode program based on 50 snapshots. ${ }^{87}$

\subsection{Calculations of cross-correlation map}

By now, the cross-correlation map has been an effective approach to probe internal dynamics of proteins and can efficiently reveal details of movement modes between residues in proteins. The cross-correlation coefficient $C_{i j}$ of each pair of $\mathrm{C}_{\alpha}$ atoms $i$ and $j$ can be generated using MD trajectories based on the following equation. ${ }^{\mathbf{8 8 , 8 9}}$

$$
C_{i j}=\frac{\left\langle\Delta r_{i} \cdot \Delta r_{j}\right\rangle}{\left(\left\langle\Delta r_{i}^{2}\right\rangle\left\langle\Delta r_{j}^{2}\right\rangle\right)^{1 / 2}}
$$

where $\Delta r_{i}$ represents the displacement from the averaged position of the $i$ th $\mathrm{C}_{\alpha}$ atom. The values of the cross-correlation coefficient $C_{i j}$ range from -1 to 1 . The positive $C_{i j}$ are indicator of the correlated motions between residues $i$ and $j$, while the negative $C_{i j}$ characterize the anticorrelated movements of residue $i$ relative to $j$. In this work, the CPPTRAJ module in AMBER 16 was applied to compute the cross-correlation map.
The extent of correlated motions between residues is displayed in color-coded modes.

\section{Results and discussion}

\subsection{Structural stability and flexibility of MD simulations}

To evaluate equilibrium and stability of MD simulations, rootmean-square deviations (RMSDs) of backbone atoms in Hsp90 relative to the first structure were computed based on MD trajectories. The function of RMSD for backbone atoms $v s$. the simulated time is depicted in ESI Fig. S1. $\dagger$ It is observed that all four systems basically reach the equilibrium after $100 \mathrm{~ns}$ of MD simulations. The RMSD values of the apo Hsp90, YK9-, YKJ- and YKI-Hsp90 compounds are 2.37, 1.99, 1.51 and $1.52 \AA$ after the equilibrium of systems, respectively, and inhibitor bindings decrease the RMSD values of Hsp90 complexed with inhibitors compared to the apo system. Furthermore, the fluctuation of RMSDs in four systems are lower than $0.6 \AA$. This result suggests that the equilibrium of systems is reliable for the following analysis of conformational changes for Hsp90 and calculations of binding free energies.

To check the stability of three inhibitors in the binding pocket of Hsp90 during MD simulations, RMSDs of nonhydrogen atoms in inhibitors relative to the first structure were calculated through the entire MD simulations (Fig. S2A $\dagger$ ). It is seen that the RMSD values of three inhibitors are lower than $1.35 \AA$, which suggests that three inhibitors are stable in the binding pocket of Hsp90. The previous studies proved that structural cluster analysis can better reveal the binding poses of inhibitors in the binding pocket of Hsp90. ${ }^{61,62}$ Thus we performed the structural cluster analyses of inhibitors on the RMSDs with a cut-off of $0.5 \AA$ using the CPPTRAJ module in Amber (Fig. S2B-D $\dagger$ ). The results indicate that YK9 has a binding pose, while YKJ and YKI have two binding poses, which implies that YK9 should have different binding modes from YKJ and YKI.

Root-mean-square fluctuations (RMSFs) of residues are usually used to evaluate structural flexibility of proteins. In this work, RMSFs of $\mathrm{C}_{\alpha}$ atoms in Hsp90 were computed using the equilibrated MD trajectories (Fig. 2). The RMSFs of the Nterminus, the residues $\mathbf{1 0 0 - 1 1 0}$ and the region near the residue 180 are increased relative to the apo Hsp90, which shows that the structural flexibility of these residues are strengthened by bindings of three inhibitors. However, the RMSFs of the domains aside from the N-terminus, the residues 100-110 and the region near the residue 180 are decreased by inhibitor bindings compared to the apo Hsp90, which suggests that the flexibility of the above domains are weakened due to the presence of three inhibitors. This result may imply that the hot spot of inhibitor-residue interactions occurs in the domains of the obvious changes in the structural flexibility.

\subsection{Changes in internal dynamics of Hsp90 induced by inhibitor bindings}

The changes in conformations and internal dynamics of targeting proteins are of significance for drug designs. In this 


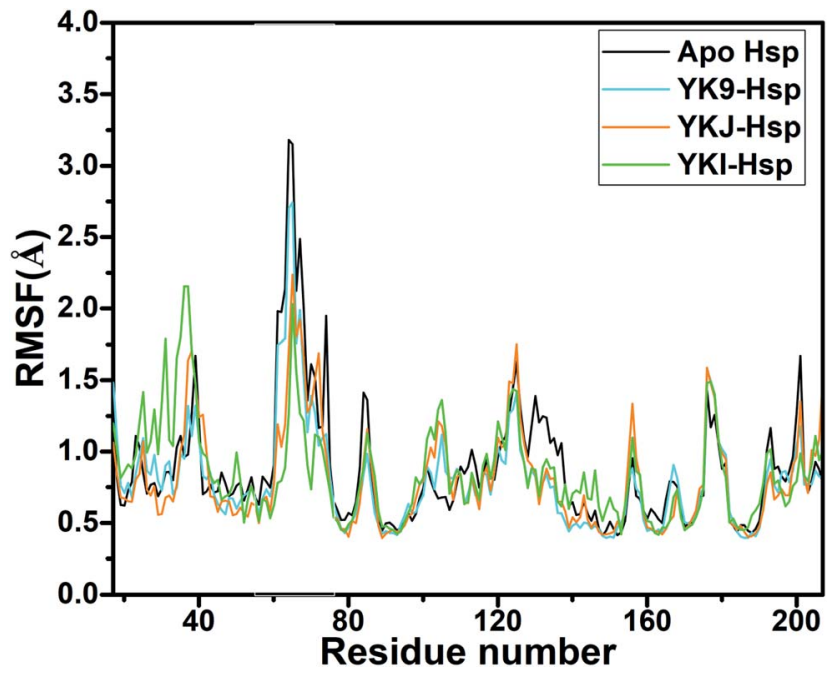

Fig. 2 Root-mean-square fluctuations (RMSFs) of $\mathrm{C}_{\alpha}$ atoms in $\mathrm{Hsp} 90$.

work, the cross-correlation maps of residues in Hsp90 were computed based on the equilibrated MD trajectories to probe the changes in the motion modes of Hsp90 caused by inhibitor bindings (Fig. 3). The strongly correlated motions between specific residues were reflected in red and yellow, while the strongly anticorrelated movements were indicated in blue or dark blue. It is observed from Fig. 3 that inhibitor bindings really induce obvious changes in the motion modes of Hsp90.

For the apo Hsp90 (Fig. 3A), the strongly correlated motions occur in the regions R1, R2, R3 and R4 (yellow and red). The regions R1 and R2 reflect the correlated motions of residues 4887 and 144-178 relative to themselves. The motions in the region R3 represent the correlated motions of residues 85-100 relative to residues $43-78$, and the region $\mathrm{R} 4$ describes the correlated movements between residues 178-186 and 138-156. In addition, the obviously anticorrelated motions are observed in the regions R5 and R6 (blue), in which the region R5 reflects the anticorrelated movements between residues 110-145 and $40-68$, and the region R6 characterizes the anticorrelated motions of the C-terminus of Hsp90 relative to residues 50-80. Compared to the apo Hsp90, bindings of three inhibitors obviously weaken the correlated motions occurring in the regions R1, R2, R3 and R4 (Fig. 3B-D). Differently, the YK9 binding weakens the anticorrelated movements of the region R5 (Fig. 3B), but the bindings of YKJ and YKI highly strengthen the anticorrelated motion in the region R5. In addition, the presence of YKI in Hsp90 also increases the anticorrelated movement of the region R7 compared to the apo Hsp90 (Fig. 3D).

To further probe the conformational changes of Hsp90 due to inhibitor bindings, PC analysis was performed to obtain
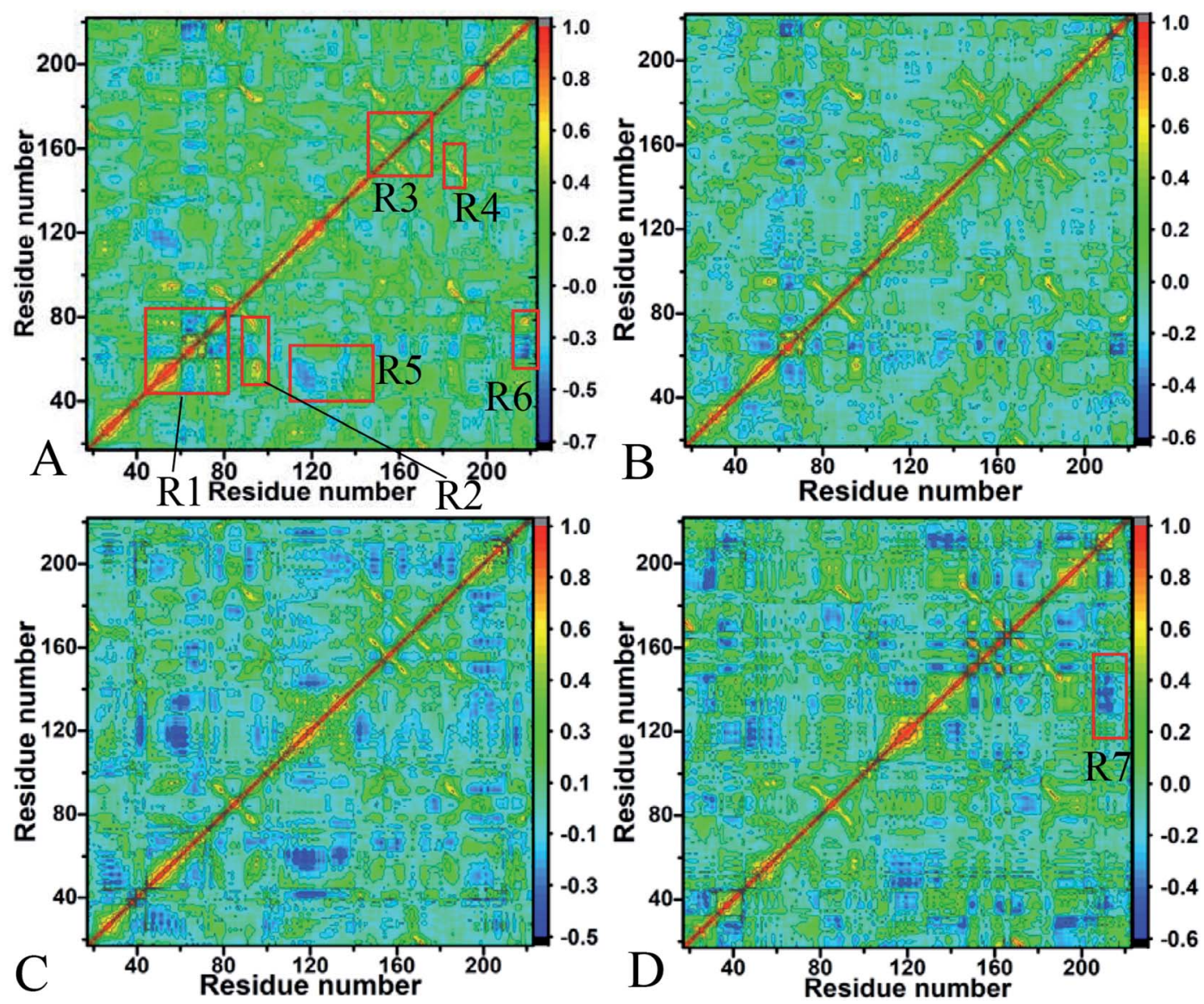

Fig. 3 Cross-correlation maps of the fluctuations of the coordinates for $\mathrm{C}_{\alpha}$ atoms of $\mathrm{Hsp} 90$ around the mean positions after the equilibration of MD simulations: (A) the apo Hsp90, (B) the YK9-bounded Hsp90, (C) the YKJ-bounded Hsp90 and (D) the YKI-bounded Hsp90. 


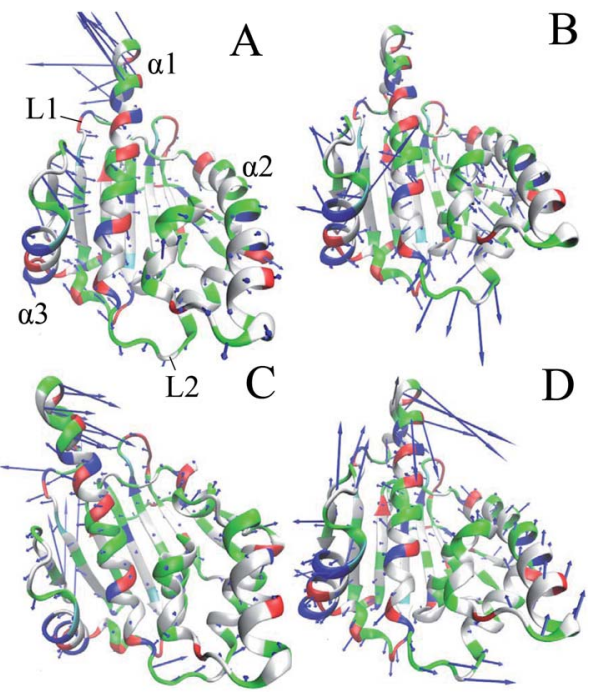

Fig. 4 Collective motions corresponding to the first principal component PC1 obtained by performing principal component analysis (PCA) on the equilibrated MD trajectories: (A) the unbounded Hsp90, (B) the YK9-bounded Hsp90, (C) the YKJ-bounded Hsp90 and (D) the YKI-bounded Hsp90.

eigenvalues and eigenvectors by constructing a covariance matrix using the atom coordinates from MD trajectories. Fig. $33 \uparrow$ gives the function of the eigenvalues $v s$. the eigenvector indices, which reflects the motion strength of Hsp90 in the apo and bounded states. The first three principal components account for $78.21 \%, 70.02 \%, 64.58 \%$ and $63.61 \%$ of the total motion observed in the last $100 \mathrm{~ns}$ of MD simulations. It is seen that inhibitor bindings highly weaken the motion strength of Hsp90 in the bounded state. The changes in the direction of motions can be captured by the eigenvectors obtained from PC analysis, which are depicted in four porcupine plots (Fig. 4). It is noted that inhibitor bindings produce significant effect on the motions of the helixes $\alpha 1, \alpha 3$ and the loops L1 and L2. In the apo Hsp90, $\alpha 1$ has a strong tendency of upward and outward motions, meanwhile the helix $\alpha 2$ and the loop L2 have weak tendency of outward motions. On the contrary, the helix $\alpha 3$ and the loop L1 produce strong tendency of inward movements. Compared to the apo Hsp90, the YK9 binding heavily inhibits the motion strength of $\alpha 1$ (Fig. 4B), while the bindings of YKJ and YKI extremely change the motion direction of $\alpha 1$ (Fig. 4C and D). Commonly, the bindings of all three inhibitors make L1 and $\alpha 3$ produce the outward motion direction. According to Fig. $4 \mathrm{~B}-\mathrm{D}$, the presences of three inhibitors in Hsp90 not only change the motion direction of the loop L2, but also strengthen the movement of L2 compared to the apo Hsp90. In addition, the association of YKI with Hsp90 also strengthens the motion of the helix $\alpha 2$ (Fig. 4D).

To better understand the conformational changes of Hsp90 induced by inhibitor bindings, free energy landscapes, contributing important information of different conformations sampled by proteins, were constructed by using projections of MD trajectories on the eigenvectors of the first two principal components PC1 and PC2 (Fig. 5). It is seen that the bindings of three inhibitors induce obvious redistribution of the conformation of Hsp90. Fig. 5A suggests that the apo Hsp90 spans six different subspaces and energy basins, which shows that Hsp90 has the conformation diversity in the unbounded state. According to Fig. 5B-D, the associations of three inhibitors with Hsp90 lead to the conformational convergence. In the bounded state of YK9 and YKJ, Hsp90 tends to have four main conformational subspaces (Fig. 5B and C), while the presence of YKI makes Hsp90 redistribute in three conformational subspaces (Fig. 5D). To better understand the conformational changes, the cluster analysis was performed on MD trajectories using the RMSD values of $\mathrm{C}_{\alpha}$ atoms in Hsp90 and the CPPTRAJ program (Fig. S4 $\dagger$ ) and the cutoff used this analysis is $2.0 \AA$. The results indicate that the apo, YK9-, YKJ- and YKI-Hsp90 have six, four, four and three clusters, which agrees basically with our current PC analysis. The above analyses suggest that the YKI binding induces the most obvious conformational changes among three inhibitors.

Based on the above analysis, the bindings of YK9, YKJ and YKI produce extremely different effect on the motion modes, internal dynamics and conformations of Hsp90. According to Fig. $1 \mathrm{C}$ and $\mathrm{D}$, the main difference in the structures of three inhibitors comes from the substitutions of two groups G1 and G2 with polar nitrogen atom. These two substitutions increase the size of YKJ and YKI relative to YK9, which must lead to more interaction contacts with the residues in the binding pocket of Hsp90, further induce the conformational changes of Hsp90 and affect the bindings of inhibitors to Hsp90.

\subsection{Calculations of binding free energies}

To evaluate binding ability of three inhibitors to Hsp90, MMPBSA and MM-GBSA methods were applied to compute binding free energies of YK9, YKJ and YKI to Hsp90. The results calculated by MM-PBSA were listed in Table 1 and that computed by MM-GBSA were given in Table S1. $\dagger$ Although the binding free energies predicted by two methods are extremely higher than the experimentally determined values, it is encouraging that the rank of our predicted binding free energies using two methods is in agreement with the one determined by the experimental data. For two methods, the results calculated by MM-GBSA are higher than that computed by MMPBSA.

According to Table 1, binding free energies of YK9, YKJ and YKI to Hsp90 are $-10.44,-14.01$ and $-15.48 \mathrm{kcal} \mathrm{mol}^{-1}$, respectively. It is found that binding free energies of inhibitors to Hsp90 consist of van der Waals interactions $\left(\Delta E_{\mathrm{vdW}}\right)$, electrostatics interactions $\left(\Delta E_{\text {ele }}\right)$, polar solvation energies $\left(\Delta G_{\text {pol }}\right)$, nonpolar solvation energies $\left(\Delta G_{\text {nonpol }}\right)$ and the entropy changes $(-T \Delta S)$. The van der Waals interactions and nonpolar solvation energies contribute advantageous forces to inhibitor bindings, but the entropy changes impair the association of inhibitors with Hsp90. Although the electrostatics interaction favors inhibitor bindings, this favorable factor is fully encountered by the polar solvation energies to produce unfavorable forces ( $\left.\Delta E_{\text {ele+pol }}\right)$ for inhibitor bindings to Hsp90. The results from the MM-GBSA calculations (Table S1 $\dagger$ ) also give similar analysis to the MM-PBSA calculations. As shown in Table 1, binding free 

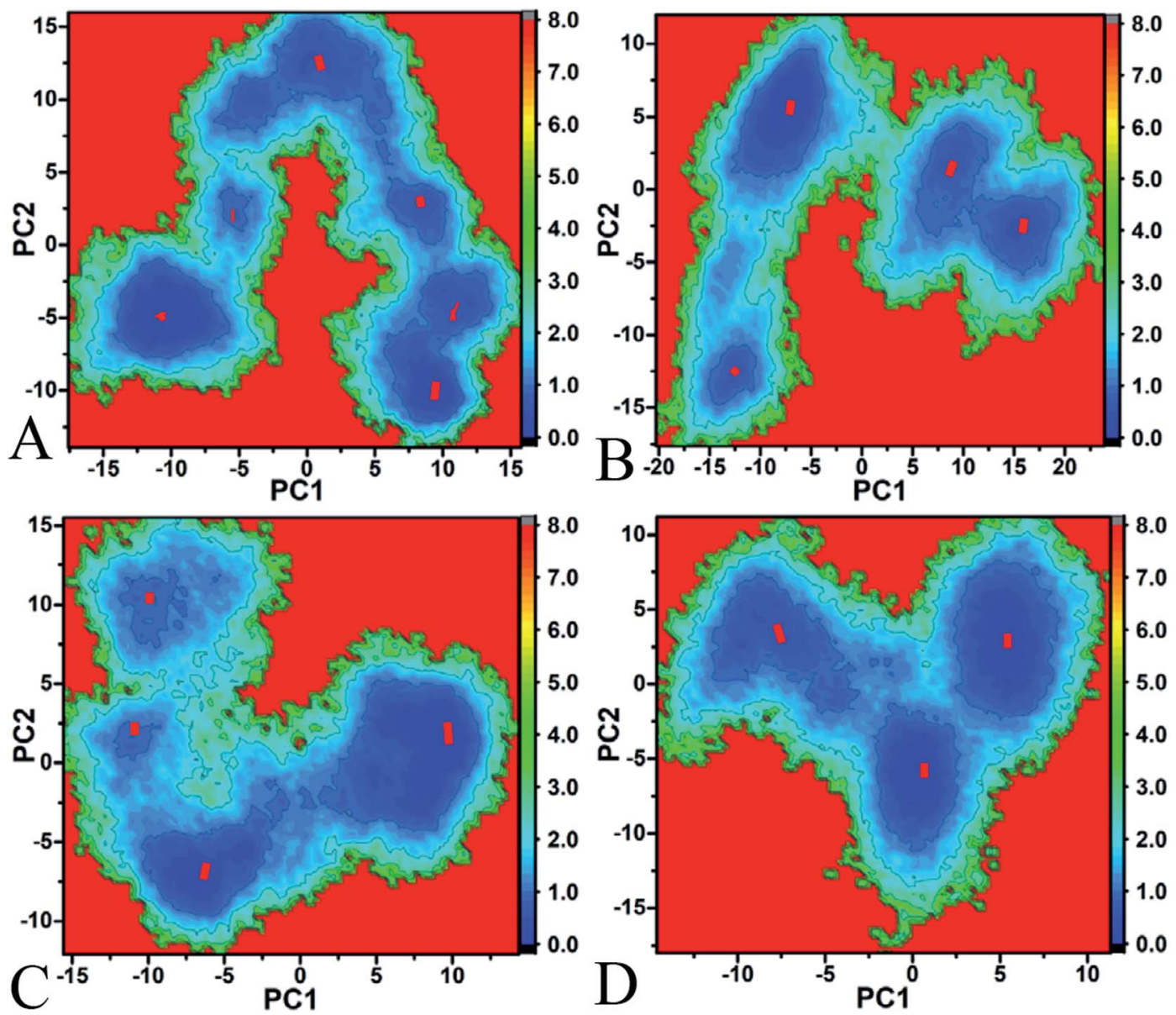

Fig. 5 Free energy landscapes of Hsp90 constructed using projection of MD trajectories on the first two principal components PC1 and PC2 from the diagonalization of covariance matrix: (A) the apo Hsp90, (B) the YK9-bounded Hsp90, (C) the YKJ-bounded Hsp90 and (D) the YKIbounded Hsp90.

Table 1 Binding free energies of inhibitors to Hsp90 calculated by MM-PBSA method

\begin{tabular}{|c|c|c|c|c|c|c|}
\hline \multirow[b]{2}{*}{${ }^{a}$ Components } & \multicolumn{2}{|c|}{ YKC-Hsp } & \multicolumn{2}{|l|}{ YKJ-Hsp } & \multicolumn{2}{|l|}{ YKI-Hsp } \\
\hline & Average & ${ }^{b} \mathrm{STD}$ & Average & STD & Average & STL \\
\hline$\Delta E_{\text {ele }}$ & -14.75 & 3.01 & -16.98 & 4.30 & -35.95 & 4.1 \\
\hline$\Delta E_{\mathrm{vdW}}$ & -45.10 & 2.74 & -46.09 & 3.02 & -60.70 & \\
\hline$\Delta G_{\mathrm{pol}}$ & 35.28 & 2.42 & 32.71 & 3.44 & -6.37 & 0.1 \\
\hline$\Delta G_{\text {nonpol }}$ & -4.84 & 0.07 & -4.94 & 0.10 & 61.54 & 4.1 \\
\hline${ }^{c} \Delta G_{\text {ele+pol }}$ & 20.53 & 2.85 & 15.73 & 3.32 & 25.59 & 4.3 \\
\hline$-T \Delta S$ & 18.97 & 1.98 & 21.29 & 1.99 & 26.90 & \\
\hline$\Delta G_{\text {bind }}$ & -10.44 & & -14.01 & & -15.48 & \\
\hline${ }^{d} \Delta G^{\exp }$ & -6.96 & & -8.50 & & -10.31 & \\
\hline
\end{tabular}

${ }^{a}$ All components of free energies are in $\mathrm{kcal} \mathrm{mol}^{-1} .{ }^{b}$ Standard errors. ${ }^{c} \Delta G_{\text {ele }+ \text { pol }}=\Delta E_{\text {ele }}+\Delta G_{\text {pol }} .{ }^{d}$ The experimental values were derived from the experimental $K_{i}$ values in reference using the equation $\Delta G^{\exp }=$ $-R T \ln K_{i}$.

energies of YKJ and YKI to Hsp90 are increased by 3.57 and $5.04 \mathrm{kcal} \mathrm{mol}^{-1}$ compared to that of YK9 to Hsp90, respectively. According to Table $\mathrm{S} 1, \dagger$ binding affinities of $\mathrm{YKJ}$ and $\mathrm{YKI}$ are 3.24 and $4.96 \mathrm{kcal} \mathrm{mol}^{-1}$ stronger than YK9, separately. The computational comparison of two methods not only suggest that our current results are reliable, but also prove that binding ability of YKJ and YKI to Hsp90 is stronger than YK9. The comparison of separate free energy components from Table 1 further reveals that van der Waals interaction of YKJ and YKI with Hsp90 are increased by 0.99 and $15.6 \mathrm{kcal} \mathrm{mol}^{-1}$ relative to that of YK9 with Hsp90, respectively, and the electrostatic interactions of YKJ and YKI with Hsp90 are strengthened by 2.23 and $21.20 \mathrm{kcal} \mathrm{mol}^{-1}$ relative to YKJ. In addition, the nonpolar solvation energies caused by the bindings of YKJ and YKI are increased by 0.10 and $1.53 \mathrm{kcal} \mathrm{mol}^{-1}$ compared to YK9, respectively. According to Fig. $1 \mathrm{C}-\mathrm{E}$, the hydrophobic rings in the G1 and G2 groups of YKJ and YKI may increase the hydrophobic contacts with the hydrophobic residues in Hsp90 relative to YK9, and the polar nitrogen atoms in the G1 and G2 groups may bring new hydrogen bonding interactions with Hsp90 compared to YK9, which improves the van der Waals interactions and electrostatics interactions of YKJ and YKI with Hsp90. This result also agrees well with the experimental results from Vallée et al. ${ }^{64}$

\subsection{Identification of inhibitor-residue interaction hot spot}

To identify the hot spot of the inhibitor-residue interaction and probe the contributions of separate residues to inhibitor 
bindings, the residue-based free energy decomposition method was applied to compute the interactions of inhibitors with separate residues of Hsp90 (Fig. 6). To compare with the calculations of inhibitor-residue interactions, scanning of hydrophobic contacts and hydrogen bond contacts of inhibitors with Hsp90 was performed on the entire MD trajectories by using the LIGPLOT program. ${ }^{90}$ In our current scanning, the default parameters from LIGPLOT were applied to define hydrogen bond and hydrophobic contacts. The function of hydrophobic contacts and hydrogen bond contacts vs. the simulation time were depicted in Fig. 7 and S5, $\dagger$ respectively. The statistical results of hydrophobic contacts and hydrogen bond contacts were displayed in Fig. 8 and S6. $\uparrow$ Meanwhile, the CPPTRAJ program was employed to analyze the hydrogen

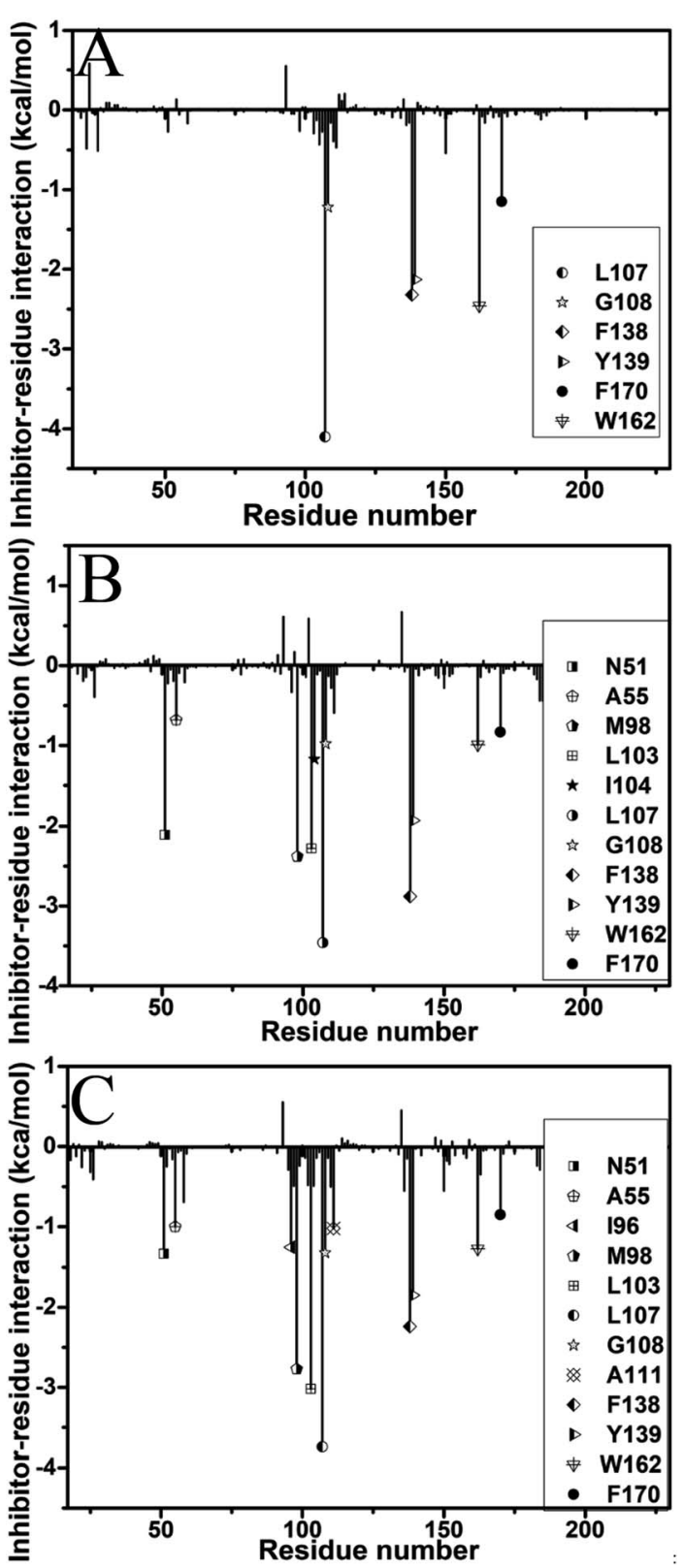

Fig. 6 Inhibitor-residue interactions calculated by using residuebased free energy decomposition: (A) YK9, (B) YKJ and (C) YKI. bonding interactions of inhibitors with Hsp90 and the corresponding information was listed in Table 2. In addition, the geometry position involving hydrophobic contacts and hydrogen bonding interactions are separately displayed in Fig. 9 and $\mathrm{S} 7 \dagger$ by using the lowest energy structures extracted from MD trajectories.

For the inhibitor YK9, Fig. 6A suggests that YK9 can produce interactions stronger than $1.0 \mathrm{kcal} \mathrm{mol}^{-1}$ with six residues of Hsp90, including L107, G108, F138, Y139, W162 and F170. Scanning of hydrophobic contacts between YK9 and Hsp90 also shows that YK9 forms stable hydrophobic contacts with these six residues of Hsp90 (Fig. 7A). The interaction energy of L107 with YK9 are $-4.10 \mathrm{kcal} \mathrm{mol}^{-1}$ (Fig. 6A). This interaction
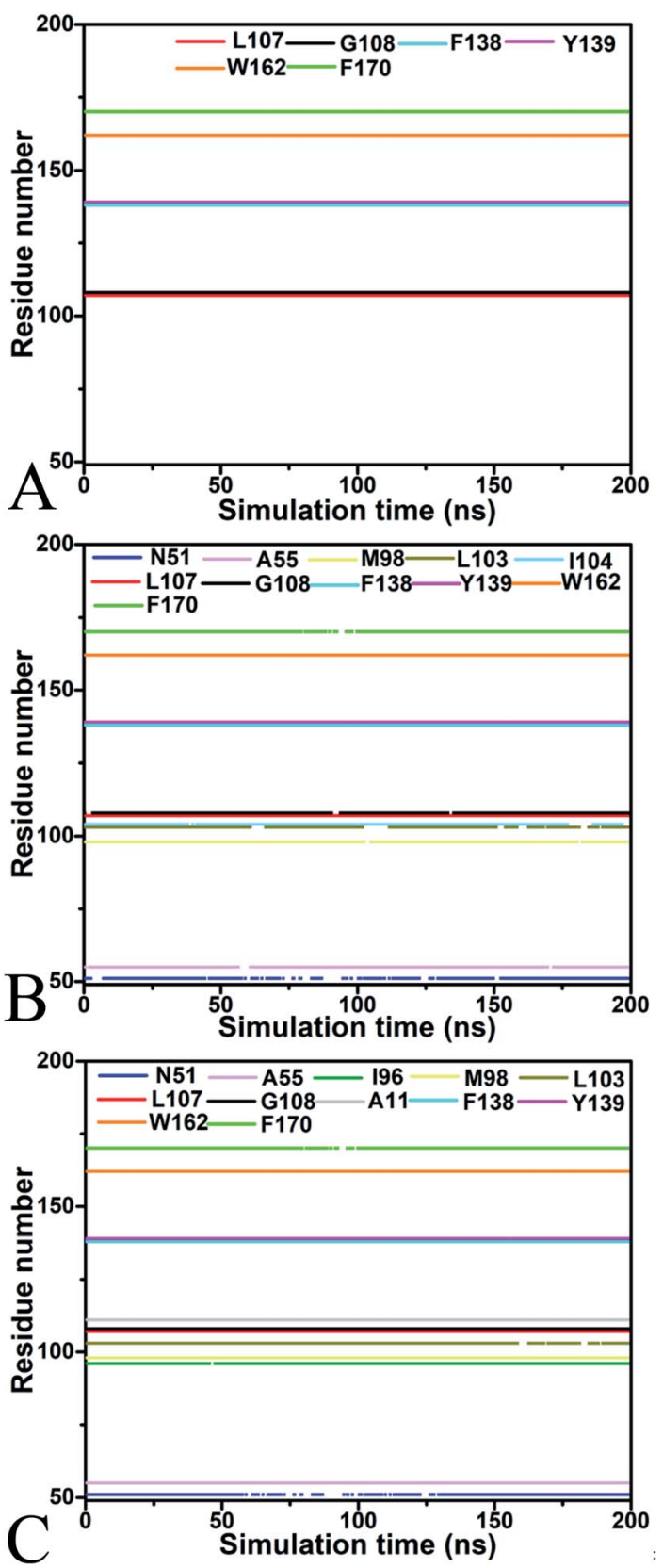

Fig. 7 The function of hydrophobic contacts between inhibitors and Hsp90 vs. the simulation time: (A) YK9, (B) YKJ and (C) YKI. 


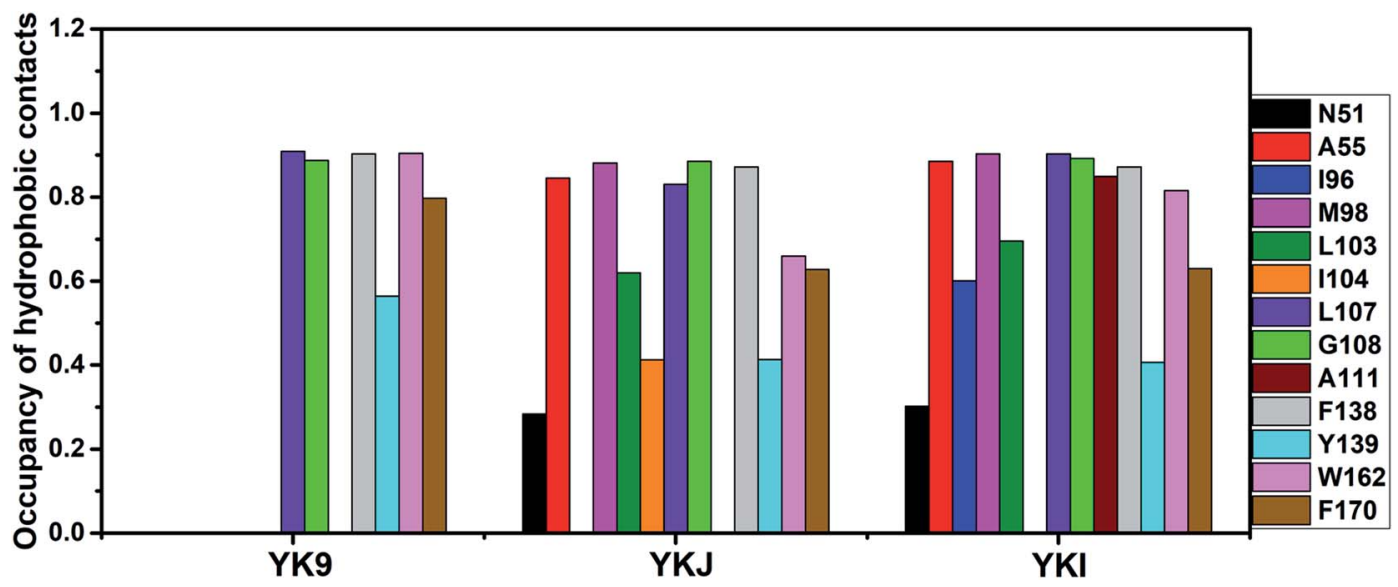

Fig. 8 Statistical analyses of hydrophobic contacts between inhibitors and separate residues of Hsp90. In the current work, the occupancy is defined as the number of conformations forming the $\mathrm{C}-\mathrm{C}$ atom contacts accounting for the percentage of the total number of conformations recorded in MD trajectories.

structurally comes from the $\mathrm{CH}-\pi$ interaction of the alkyl in L107 with the hydrophobic ring R1 (Fig. 9A), which is supported by the hydrophobic contact occupancy of $90.9 \%$ between L107 and YK9 (Fig. 8). According to Fig. 9A and S7A, $\dagger$ Y139 structurally generates two classes of interactions, one stems from the $\pi-\pi$ interaction between the ring R1 of YK9 and the phenyl of Y139, another origins from the hydrogen bonding interaction with the occupancy of $94.37 \%$ between the nitrogen atom N12 of YK9 and the oxygen atom OH of Y139 (Table 2, Fig. S5A $\dagger$ and $\mathrm{S} 6 \mathrm{~A})$. These two interactions totally contribute the interaction energy of $-2.13 \mathrm{kcal} \mathrm{mol}^{-1}$ to the YK9 binding (Fig. 6A). Scanning of hydrophobic contacts finds that the ring R3 of YK9 forms the stable $\pi-\pi$ contacts with F138 and W162 though MD simulations (Fig. 7A and 9A). The number of conformations detecting the hydrophobic contacts of YK9 with F38 and W162 separately account for $90.3 \%$ and $90.4 \%$ of the total conformations from MD trajectories (Fig. 8), which provides the energy contributions of -2.32 and $-2.62 \mathrm{kcal} \mathrm{mol}^{-1}$ for the YK9 binding (Fig. 6A). As shown in Fig. 9A, the carbon atom of G108 and the phenyl of F170 structurally close the hydrophobic ring $\mathrm{R} 2$ of $\mathrm{YK} 9$, which are easy to respectively produce the $\mathrm{CH}-\pi$ and $\pi-\pi$ interactions between them. These two interactions are not only supported by scanning of hydrophobic contacts (Fig. 7A and 8), but also contribute the interaction energies of -1.22 and $-1.15 \mathrm{kcal} \mathrm{mol}^{-1}$ to the YK9 binding (Fig. 6A).
Similar to YK9, YKJ also generates favorable interactions with the residues L107, G108, F138, Y139, W162 and F170 of Hsp90 (Fig. 6B), which is supported by scanning of hydrophobic contacts between YKJ and Hsp90 as well as statistical analysis of hydrophobic contacts (Fig. 7B and 8). The interaction modes of these six residues with YKJ are also similar to YK9 (Fig. 9B). A hydrogen bond with the occupancy of $92.22 \%$ is also identified between the oxygen atom $\mathrm{OH}$ of Y139 and the nitrogen atom N3 of YKJ (Table 2, Fig. S5B, S6 and S7B $†$ ). Due to the substitution of the group G1 (Fig. 1D), several additional interactions of YKJ with N51, A55, G97, M98 and I104 are detected (Fig. 6B, 7B and S5B $\dagger$ ). The CPPTRAJ analysis shows that YK9 constructs two hydrogen bonding interactions with G97 and L103 (Table 2), which agrees well with scanning of hydrogen bond contacts (Fig. S5B, S6 and S7B $\uparrow$ ). In addition, L103 also forms stable hydrophobic contacts with YKJ (Fig. 7B, 8 and 9B). Totally, L103 provides the energy contribution of $-2.28 \mathrm{kcal} \mathrm{mol}^{-1}$ for the YKJ binding to Hsp90 (Fig. 6B). Structurally, the carbon atom C of N51 and the alkyls of A55 and M98 are located near the ring R4 of YKJ (Fig. 9B) and are easy to generate the $\mathrm{CH}-\pi$ interactions between them, which is supported by scanning of hydrophobic contacts of YKJ with Hsp90 (Fig. 7B and 8). Thus, N51, A55 and M98 independently contribute the interaction energies of $-2.11,-0.68$ and $-2.38 \mathrm{kcal} \mathrm{mol}^{-1}$ to the YKJ binding to Hsp90 (Fig. 6B). It is observed that an additional interaction of

Table 2 Main hydrogen bonding interactions of inhibitors with Hsp90

\begin{tabular}{llll}
\hline Hydrogen bonds & ${ }^{a}$ Distance $(\AA)$ & ${ }^{a}$ Angle $\left({ }^{\circ}\right)$ & ${ }^{b}$ Occupancy $(\%)$ \\
\hline${ }^{c}$ YK9-N12 $\cdots$ Y139-OH-HH & $3.07 \pm 0.31$ & $137.29 \pm 7.8$ & 94.37 \\
YKJ-N6-H6 $\cdots$ G97-O & $3.32 \pm 0.24$ & $121.26 \pm 10.1$ & 23.61 \\
YKJ-N2-H3 $\cdots$ L103-O & $3.01 \pm 0.28$ & $153.72 \pm 9.6$ & 67.60 \\
YKJ-N3 $\cdots$ Y139-OH-HH & $2.96 \pm 0.35$ & $158.38 \pm 11.2$ & 92.22 \\
YKI-O13 $\cdots$ N51-ND2-HD22 & $3.02 \pm 0.21$ & $132.61 \pm 8.4$ & 43.28 \\
YKI-N2-H3 $\cdots$ L103-O & $3.02 \pm 0.44$ & $147.93 \pm 8.9$ & 64.31 \\
YKI-N3 $\cdots$ Y139-OH-HH & $2.92 \pm 0.26$ & $159.52 \pm 11.6$ & 98.80
\end{tabular}

${ }^{a}$ Hydrogen bonds are determined by the acceptor $\cdots$ donor distance of $<3.5 \AA$ and acceptor $\cdots \mathrm{H}$-donor angle of $>120^{\circ}$. ${ }^{b}$ Occupancy $(\%)$ is defined as the percentage of simulation time that a specific hydrogen bond exists. ${ }^{c}$ The full lines indicate chemical bonds, and the dotted lines describe hydrogen bonding interactions. 


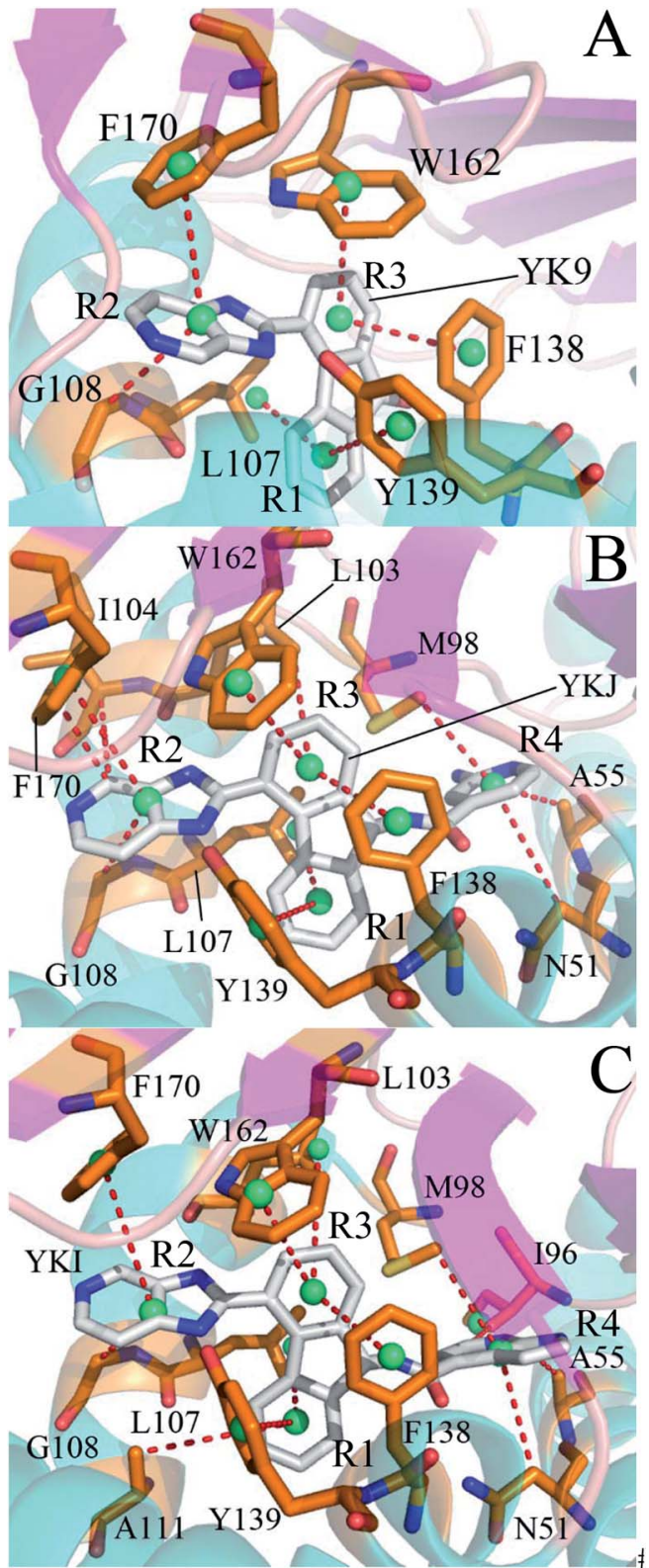

Fig. 9 Key residues of Hsp90 forming hydrophobic contacts with three inhibitors. Key residues and inhibitors are shown in stick modes. A pair of carbon atoms following the default parameters of LIGPLOT in distances are defined as hydrophobic contacts.

$-1.17 \mathrm{kcal} \mathrm{mol}^{-1}$ occurs between YK9 and I104 (Fig. 6B and 8), which is in consistence with scanning of hydrophobic contacts on MD trajectories (Fig. 7B). This interaction structurally comes from the $\mathrm{CH}-\pi$ interaction of the alkyl in I104 with the ring R2 of YKJ.

By comparison with YK9, YKI also generates similar interactions with six residues L107, G108, F138, Y139, W162 and F170 (Fig. 6C), which agree well with scanning of hydrophobic contacts between YKI and Hsp90 (Fig. 7C and 8). A common hydrogen bond with the high occupancy of $98.80 \%$ is detected between the oxygen atom $\mathrm{OH}$ of Y139 and the nitrogen atom N3 of YKI (Table 2, Fig. S5C and S6†). It is found that the substitution of the group G2 (Fig. 1E) brings several additional interactions of YKI with five residues N51, A55, I96, M98 and L103. Among these five residues, the carbon atom of N51 and the alkyl of $\mathrm{L} 103$ separately produce the $\mathrm{CH}-\pi$ interactions with the rings R4 and R3 (Fig. 9C), moreover the nitrogen atom ND2 of N51 and the oxygen atom O of L103 form the hydrogen bonding interactions with the nitrogen atoms N3 and N2 of YKI (Fig. S5C, S6 and $\mathrm{S7C} \uparrow$ ), respectively, corresponding to the occupancy of $43.28 \%$ and $64.31 \%$ (Table 2). Totally, N51 and L103 independently contribute the interaction energies of -1.33 and $-3.02 \mathrm{kcal} \mathrm{mol}^{-1}$ to the YKI binding to Hsp90 (Fig. 6C). As shown in Fig. 9C, the alkyls of A55, I96 and M98 structurally close the G2 group (namely the hydrophobic ring $\mathrm{R} 4$ ) and are easy to produce the $\mathrm{CH}-\pi$ interactions between them. A55, I96 and M98 respectively provide the energy contributions of $-1.00,-1.25$ and $-2.77 \mathrm{kcal} \mathrm{mol}^{-1}$ to the YKI association with Hsp90 (Fig. 6C). The current analysis based on identifying the hot spot of the inhibitor-residue interactions basically agrees with the experimental results from Vallée et al. ${ }^{64}$

Based on the above analyses of the residue-based free energy decomposition and scanning of hydrophobic contacts and hydrogen bond contacts between inhibitors and Hsp90, the $\mathrm{CH}-\pi, \pi-\pi$ and hydrogen bonding interactions play significant role in bindings of inhibitors to Hsp90. Six common residues L107, G108, F138, Y139, W162 and F170 are identified as the hot spot involving the interactions of YK9, YKJ and YKI with Hsp90. Compared to YK9, the substitution of the group G1 in YKJ not only leads to hydrogen bonding interactions with G97 and L103, but also produces hydrophobic interactions with N51, A55, M98 and I104. Similar to YKJ, the introduction of the Group G2 into YKI also brings two hydrogen bonding interactions with N51 and L103, meanwhile generates hydrophobic interactions with N51, A55, M98 and L103. These additional interactions induced by the substitutions of G1 and G2 can be used as new drug target toward Hsp90.

\section{Conclusions}

In this work, $200 \mathrm{~ns} \mathrm{MD}$ simulations were performed on the apo Hsp90 and three inhibitor-Hsp90 complexes to explore binding modes of inhibitors to Hsp90. The RMSFs demonstrate that the associations of inhibitors heavily affect the flexibility of Hsp90. The equilibrated MD trajectories were used for PC analysis and the results suggest that inhibitor bindings produce important effect on the conformational changes, internal dynamics and motion modes of Hsp90, especially for the helix $\alpha 1$ and the loops L1 and L2. Binding affinities of inhibitors to Hsp90 were computed based on 200 snapshots extracted from the equilibrated MD trajectories and the results show that binding ability of YKJ and YKI is stronger than YK9. Furthermore, the substitutions of two groups G1 and G2 in YKJ and YKI not only increase the van der Waals interactions of YKJ and YKI with Hsp90 compared to YK9, but also improve the electrostatics interactions of YKJ and YKI with Hsp90. According to scanning of inhibitor-residue interactions and residue-based on free energy decomposition, the substitution of the group G1 in YK9 not only leads to two additional hydrogen bonding interactions with G97 and L103, but also produces hydrophobic interactions 
with N51, A55, M98 and I104 compared to YK9. The introduction of the Group G2 into YKI also brings two hydrogen bonding interactions with N51 and L103, meanwhile generates hydrophobic interactions with N51, A55, M98 and L103. We also expect that this study can contribute theoretical hints for design of potent inhibitors toward Hsp90.

\section{Conflicts of interest}

There are no conflicts to declare.

\section{Acknowledgements}

This work is supported by the National Key Research and Development Program (Grant 2016YFA0502301), the National Natural Science Foundation of China (21403283, 11274206, 11504206, 81273435, and 81573350). Shandong Province Key Research and Development Program (No. 2016GGX102043) and Shandong Provincial Natural Science Foundation (ZR2017MA040 and ZR2015AL022). A Project of Shandong Province Higher Educational Science and Technology Program (No. J18KA040, J17KA045), major development projects of Shandong Jiaotong University and CAS Key Laboratory of Receptor Research (SIMM1706YKF-03).

\section{References}

1 M. Taipale, D. F. Jarosz and S. Lindquist, Nat. Rev. Mol. Cell Biol., 2010, 11, 515-528.

2 T. Didenko, A. M. S. Duarte, G. E. Karagöz and S. G. D. Rüdiger, Biochim. Biophys. Acta, Mol. Cell Res., 2012, 1823, 636-647.

3 M. E. Feder and G. E. Hofmann, Annu. Rev. Physiol., 1999, 61, 243-282.

4 C. Garrido, S. Gurbuxani, L. Ravagnan and G. Kroemer, Biochem. Biophys. Res. Commun., 2001, 286, 433-442.

5 L. Neckers and P. Workman, Clin. Cancer Res., 2012, 18, 6476.

6 L. H. Pearl and C. Prodromou, Annu. Rev. Biochem., 2006, 75, 271-294.

7 A. Maloney and P. Workman, Expert Opin. Biol. Ther., 2002, 2, 3-24.

8 D. L. Penkler, C. Atilgan and Ö. Tastan Bishop, J. Chem. Inf. Model., 2018, 58, 383-404.

9 F. H. Schopf, M. M. Biebl and J. Buchner, Nat. Rev. Mol. Cell Biol., 2017, 18, 345-360.

10 T. Taldone, S. O. Ochiana, P. D. Patel and G. Chiosis, Trends Pharmacol. Sci., 2014, 35, 592-603.

11 K. Moulick, J. H. Ahn, H. Zong, A. Rodina, L. Cerchietti, E. M. Gomes DaGama, E. Caldas-Lopes, K. Beebe, F. Perna, K. Hatzi, L. P. Vu, X. Zhao, D. Zatorska, T. Taldone, P. Smith-Jones, M. Alpaugh, S. S. Gross, N. Pillarsetty, T. Ku, J. S. Lewis, S. M. Larson, R. Levine, H. ErdjumentBromage, M. L. Guzman, S. D. Nimer, A. Melnick, L. Neckers and G. Chiosis, Nat. Chem. Biol., 2011, 7, 818.

12 V. C. H. Da Silva and C. H. I. Ramos, J. Proteomics, 2012, 75, 2790-2802.
13 J. Travers, S. Sharp and P. Workman, Drug Discovery Today, 2012, 17, 242-252.

14 H. Misun, M. Luigi and L. Bo, Curr. Med. Chem., 2009, 16, 3081-3092.

15 S. M. Roe, C. Prodromou, R. O'Brien, J. E. Ladbury, P. W. Piper and L. H. Pearl, J. Med. Chem., 1999, 42, 260-266.

16 M. A. Biamonte, J. Shi, K. Hong, D. C. Hurst, L. Zhang, J. Fan, D. J. Busch, P. L. Karjian, A. A. Maldonado, J. L. Sensintaffar, Y.-C. Yang, A. Kamal, R. E. Lough, K. Lundgren, F. J. Burrows, G. A. Timony, M. F. Boehm and S. R. Kasibhatla, J. Med. Chem., 2006, 49, 817-828.

17 M. A. Biamonte, R. Van de Water, J. W. Arndt, R. H. Scannevin, D. Perret and W.-C. Lee, J. Med. Chem., 2010, 53, 3-17.

18 J. R. Porter, C. C. Fritz and K. M. Depew, Curr. Opin. Chem. Biol., 2010, 14, 412-420.

19 S. R. Kasibhatla, K. Hong, M. A. Biamonte, D. J. Busch, P. L. Karjian, J. L. Sensintaffar, A. Kamal, R. E. Lough, J. Brekken, K. Lundgren, R. Grecko, G. A. Timony, Y. Ran, R. Mansfield, L. C. Fritz, E. Ulm, F. J. Burrows and M. F. Boehm, J. Med. Chem., 2007, 50, 2767-2778.

20 C.-H. Yi, J.-Z. Chen, S.-H. Shi, G.-D. Hu and Q.-G. Zhang, Mol. Simul., 2010, 36, 454-460.

21 P. A. Brough, W. Aherne, X. Barril, J. Borgognoni, K. Boxall, J. E. Cansfield, K.-M. J. Cheung, I. Collins, N. G. M. Davies, M. J. Drysdale, B. Dymock, S. A. Eccles, H. Finch, A. Fink, A. Hayes, R. Howes, R. E. Hubbard, K. James, A. M. Jordan, A. Lockie, V. Martins, A. Massey, T. P. Matthews, E. McDonald, C. J. Northfield, L. H. Pearl, C. Prodromou, S. Ray, F. I. Raynaud, S. D. Roughley, S. Y. Sharp, A. Surgenor, D. L. Walmsley, P. Webb, M. Wood, P. Workman and L. Wright, J. Med. Chem., 2008, 51, 196-218. 22 K. H. Huang, J. M. Veal, R. P. Fadden, J. W. Rice, J. Eaves, J.-P. Strachan, A. F. Barabasz, B. E. Foley, T. E. Barta, W. Ma, M. A. Silinski, M. Hu, J. M. Partridge, A. Scott, L. G. DuBois, T. Freed, P. M. Steed, A. J. Ommen, E. D. Smith, P. F. Hughes, A. R. Woodward, G. J. Hanson, W. S. McCall, C. J. Markworth, L. Hinkley, M. Jenks, L. Geng, M. Lewis, J. Otto, B. Pronk, K. Verleysen and S. E. Hall, J. Med. Chem., 2009, 52, 4288-4305.

23 P.-P. Kung, B. Huang, G. Zhang, J. Z. Zhou, J. Wang, J. A. Digits, J. Skaptason, S. Yamazaki, D. Neul, M. Zientek, J. Elleraas, P. Mehta, M.-J. Yin, M. J. Hickey, K. S. Gajiwala, C. Rodgers, J. F. Davies and M. R. Gehring, J. Med. Chem., 2010, 53, 499-503.

24 P.-P. Kung, L. Funk, J. Meng, M. Collins, J. Z. Zhou, M. Catherine Johnson, A. Ekker, J. Wang, P. Mehta, M.-J. Yin, C. Rodgers, J. F. Davies, E. Bayman, T. Smeal, K. A. Maegley and M. R. Gehring, Bioorg. Med. Chem. Lett., 2008, 18, 6273-6278.

25 C. W. Murray, M. G. Carr, O. Callaghan, G. Chessari, M. Congreve, S. Cowan, J. E. Coyle, R. Downham, E. Figueroa, M. Frederickson, B. Graham, R. McMenamin, M. A. O'Brien, S. Patel, T. R. Phillips, G. Williams, A. J. Woodhead and A. J. A. Woolford, J. Med. Chem., 2010, 53, 5942-5955. 
26 A. J. Woodhead, H. Angove, M. G. Carr, G. Chessari, M. Congreve, J. E. Coyle, J. Cosme, B. Graham, P. J. Day, R. Downham, L. Fazal, R. Feltell, E. Figueroa, M. Frederickson, J. Lewis, R. McMenamin, C. W. Murray, M. A. O'Brien, L. Parra, S. Patel, T. Phillips, D. C. Rees, S. Rich, D.-M. Smith, G. Trewartha, M. Vinkovic, B. Williams and A. J. A. Woolford, J. Med. Chem., 2010, 53, 5956-5969.

27 D. A. Proia and R. C. Bates, Cancer Res., 2014, 74, 1294-1300. 28 H.-P. Sun, J.-M. Jia, F. Jiang, X.-L. Xu, F. Liu, X.-K. Guo, B. Cherfaoui, H.-Z. Huang, Y. Pan and Q.-D. You, Eur. J. Med. Chem., 2014, 79, 399-412.

29 E. Tzanetou, S. Liekens, K. M. Kasiotis, G. Melagraki, A. Afantitis, N. Fokialakis and S. A. Haroutounian, Eur. J. Med. Chem., 2014, 81, 139-149.

30 E. Casale, N. Amboldi, M. G. Brasca, D. Caronni, N. Colombo, C. Dalvit, E. R. Felder, G. Fogliatto, A. Galvani, A. Isacchi, P. Polucci, L. Riceputi, F. Sola, C. Visco, F. Zuccotto and F. Casuscelli, Bioorg. Med. Chem., 2014, 22, 4135-4150.

31 D. Audisio, D. Methy-Gonnot, C. Radanyi, J.-M. Renoir, S. Denis, F. Sauvage, J. Vergnaud-Gauduchon, J.-D. Brion, S. Messaoudi and M. Alami, Eur. J. Med. Chem., 2014, 83, 498-507.

32 J. Trepel, M. Mollapour, G. Giaccone and L. Neckers, Nat. Rev. Cancer, 2010, 10, 537.

33 M. Mickler, M. Hessling, C. Ratzke, J. Buchner and T. Hugel, Nat. Struct. Mol. Biol., 2009, 16, 281.

34 K. Richter, J. Soroka, L. Skalniak, A. Leskovar, M. Hessling, J. Reinstein and J. Buchner, J. Biol. Chem., 2008, 283, 17757-17765.

35 M. Hessling, K. Richter and J. Buchner, Nat. Struct. Mol. Biol., 2009, 16, 287-293.

36 T. O. Street, L. A. Lavery and D. A. Agard, Mol. Cell, 2011, 42, 96-105.

37 T. O. Street, K. A. Krukenberg, J. Rosgen, D. W. Bolen and D. A. Agard, Protein Sci., 2010, 19, 57-65.

38 M. Amaral, D. B. Kokh, J. Bomke, A. Wegener, H. P. Buchstaller, H. M. Eggenweiler, P. Matias, C. Sirrenberg, R. C. Wade and M. Frech, Nat. Commun., 2017, 8, 2276.

39 S. Lu, H. Jang, S. Muratcioglu, A. Gursoy, O. Keskin, R. Nussinov and J. Zhang, Chem. Rev., 2016, 116, 6607-6665.

40 P. Wang, T. Fu, X. Zhang, F. Yang, G. Zheng, W. Xue, Y. Chen, X. Yao and F. Zhu, Biochim. Biophys. Acta, Gen. Subj., 2017, 1861, 2766-2777.

41 G. Li, H. Shen, D. Zhang, Y. Li and H. Wang, J. Chem. Theory Comput., 2016, 12, 676-693.

42 T. Hou, W. A. McLaughlin and W. Wang, Proteins: Struct., Funct., Genet., 2008, 71, 1163-1174.

43 G. Hu, A. Ma, X. Dou, L. Zhao and J. Wang, Int. J. Mol. Sci., 2016, 17, 819.

44 L. Duan, G. Feng, X. Wang, L. Wang and Q. Zhang, Phys. Chem. Chem. Phys., 2017, 19, 10140-10152.

45 M. Yang, X. Zhang and K. Han, Proteins: Struct., Funct., Genet., 2010, 78, 2222-2237.
46 H. Sun, Y. Li, M. Shen, D. Li, Y. Kang and T. Hou, J. Chem. Inf. Model., 2017, 57, 1895-1906.

47 L. Shao-Yong, H. Zhi-Min, H. Wen-Kang, L. Xin-Yi, C. YingYi, S. Ting and Z. Jian, Proteins, 2013, 81, 740-753.

48 E. L. Wu, K.-Y. Wong, X. Zhang, K. Han and J. Gao, J. Phys. Chem. B, 2009, 113, 2477-2485.

49 T. Ichiye and M. Karplus, Proteins: Struct., Funct., Genet., 1991, 11, 205-217.

50 J. Chen, J. Wang and W. Zhu, Phys. Chem. Chem. Phys., 2017, 19, 3067-3075.

51 J. Su, X. Liu, S. Zhang, F. Yan, Q. Zhang and J. Chen, J. Biomol. Struct. Dyn., 2018, 36, 1212-1224.

52 J. Chen, RSC Adv., 2016, 6, 58573-58585.

53 L.-Q. Yang, P. Sang, R.-P. Zhang and S.-Q. Liu, RSC Adv., 2017, 7, 42094-42104.

54 L. Duan, X. Liu and J. Z. H. Zhang, J. Am. Chem. Soc., 2016, 138, 5722-5728.

55 J. Chen, J. Wang and W. Zhu, Phys. Chem. Chem. Phys., 2017, 19, 30239-30248.

56 D. Shi, Q. Bai, S. Zhou, X. Liu, H. Liu and X. Yao, Proteins: Struct., Funct., Genet., 2018, 86, 43-56.

57 G. Hu, A. Ma and J. Wang, J. Chem. Inf. Model., 2017, 57, 918928.

58 T. Hou, J. Wang, Y. Li and W. Wang, J. Comput. Chem., 2011, 32, 866-877.

59 L. L. Duan, G. Q. Feng and Q. G. Zhang, Sci. Rep., 2016, 6, 31488.

60 G. Hu, S. Xu and J. Wang, Chem. Biol. Drug Des., 2015, 86, 1351-1359.

61 G. Colombo, G. Morra, M. Meli and G. Verkhivker, Proc. Natl. Acad. Sci. U. S. A., 2008, 105, 7976-7981.

62 G. Vettoretti, E. Moroni, S. Sattin, J. Tao, D. A. Agard, A. Bernardi and G. Colombo, Sci. Rep., 2016, 6, 23830.

63 G. Morra, G. Verkhivker and G. Colombo, PLoS Comput. Biol., 2009, 5, e1000323.

64 F. Vallée, C. Carrez, F. Pilorge, A. Dupuy, A. Parent, L. Bertin, F. Thompson, P. Ferrari, F. Fassy, A. Lamberton, A. Thomas, R. Arrebola, S. Guerif, A. Rohaut, V. Certal, J.-M. Ruxer, C. Delorme, A. Jouanen, J. Dumas, C. Grépin, C. Combeau, H. Goulaouic, N. Dereu, V. Mikol, P. Mailliet and H. Minoux, J. Med. Chem., 2011, 54, 7206-7219.

65 J. Wang, P. Morin, W. Wang and P. A. Kollman, J. Am. Chem. Soc., 2001, 123, 5221-5230.

66 W. Wang and P. A. Kollman, J. Mol. Biol., 2000, 303, 567-582. 67 W. Wang and P. A. Kollman, Proc. Natl. Acad. Sci. U. S. A., 2001, 98, 14937-14942.

68 C. Wang, D. A. Greene, L. Xiao, R. Qi and R. Luo, Front. Mol. Biosci., 2018, 4, 1-18.

69 H. Sun, Y. Li, M. Shen, S. Tian, L. Xu, P. Pan, Y. Guan and T. Hou, Phys. Chem. Chem. Phys., 2014, 16, 22035-22045.

70 H. Sun, Y. Li, S. Tian, L. Xu and T. Hou, Phys. Chem. Chem. Phys., 2014, 16, 16719-16729.

71 J. Wang, Q. Shao, B. P. Cossins, J. Shi, K. Chen and W. Zhu, J. Biomol. Struct. Dyn., 2016, 34, 163-176.

72 H. Li, A. D. Robertson and J. H. Jensen, Proteins: Struct., Funct., Genet., 2005, 61, 704-721. 
73 D. C. Bas, D. M. Rogers and J. H. Jensen, Proteins: Struct., Funct., Genet., 2008, 73, 765-783.

74 D. A. Case, R. M. Betz, D. S. Cerutti, T. E. Cheatham, T. A. Darden, R. E. Duke, T. J. Giese, H. Gohlke, A. W. Goetz, N. Homeyer, S. Izadi, P. Janowski, J. Kaus, A. Kovalenko, T. S. Lee, S. LeGrand, P. Li, C. Lin, T. Luchko, R. Luo, B. Madej, D. Mermelstein, K. M. Merz, G. Monard, H. Nguyen, H. T. Nguyen, I. Omelyan, A. Onufriev, D. R. Roe, A. Roitberg, C. Sagui, C. L. Simmerling, W. M. Botello-Smith, J. Swails, R. C. Walker, J. Wang, R. M. Wolf, X. Wu, L. Xiao and P. A. Kollman, 2016, AMBER 2016, University of California, San Francisco.

75 J. A. Maier, C. Martinez, K. Kasavajhala, L. Wickstrom, K. E. Hauser and C. Simmerling, J. Chem. Theory Comput., 2015, 11, 3696-3713.

76 W. L. Jorgensen, J. Chandrasekhar, J. D. Madura, R. W. Impey and M. L. Klein, J. Chem. Phys., 1983, 79, 926935.

77 M. J. Frisch, G. W. Trucks, H. B. Schlegel, G. E. Scuseria, M. A. Robb, J. R. Cheeseman, G. Scalmani, V. Barone, B. Mennucci, G. A. Petersson, H. Nakatsuji, M. Caricato, X. Li, H. P. Hratchian, A. F. Izmaylov, J. Bloino, G. Zheng, J. L. Sonnenberg, M. Hada, M. Ehara, K. Toyota, R. Fukuda, J. Hasegawa, M. Ishida, T. Nakajima, Y. Honda, O. Kitao, H. Nakai, T. Vreven, J. A. Montgomery Jr, J. E. Peralta, F. Ogliaro, M. Bearpark, J. J. Heyd, E. Brothers, K. N. Kudin, V. N. Staroverov, R. Kobayashi, J. Normand, K. Raghavachari, A. Rendell, J. C. Burant, S. S. Iyengar, J. Tomasi, M. Cossi, N. Rega, J. M. Millam, M. Klene, J. E. Knox, J. B. Cross, V. Bakken, C. Adamo, J. Jaramillo, R. Gomperts, R. E. Stratmann, O. Yazyev,
A. J. Austin, R. Cammi, C. Pomelli, J. W. Ochterski, R. L. Martin, K. Morokuma, V. G. Zakrzewski, G. A. Voth, P. Salvador, J. J. Dannenberg, S. Dapprich, A. D. Daniels, O. Farkas, J. B. Foresman, J. V. Ortiz, J. Cioslowski and D. J. Fox, Gaussian 09, revision C.01, Gaussian, Inc., Wallingford, CT, 2009.

78 J. Wang, R. M. Wolf, J. W. Caldwell, P. A. Kollman and D. A. Case, J. Comput. Chem., 2004, 25, 1157-1174.

79 J.-P. Ryckaert, G. Ciccotti and H. J. C. Berendsen, J. Comput. Phys., 1977, 23, 327-341.

80 J. A. Izaguirre, D. P. Catarello, J. M. Wozniak and R. D. Skeel, J. Chem. Phys., 2001, 114, 2090-2098.

81 D. R. Roe and T. E. Cheatham, J. Chem. Theory Comput., 2013, 9, 3084-3095.

82 J. Chen, J. Wang, W. Zhu and G. Li, J. Comput.-Aided Mol. Des. , 2013, 27, 965-974.

83 http://www.pymol.org.

84 W. Humphrey, A. Dalke and K. Schulten, J. Mol. Graphics, 1996, 14, 33-38.

85 A. Onufriev, D. Bashford and D. A. Case, Proteins: Struct., Funct., Genet., 2004, 55, 383-394.

86 H. Gohlke, C. Kiel and D. A. Case, J. Mol. Biol., 2003, 330, 891-913.

87 B. R. Miller, T. D. McGee, J. M. Swails, N. Homeyer, H. Gohlke and A. E. Roitberg, J. Chem. Theory Comput., 2012, 8, 3314-3321.

88 T. Ichiye and M. Karplus, Proteins: Struct., Funct., Genet., 1991, 11, 205-217.

89 C. Jianzhong, Chem. Biol. Drug Des., 2017, 89, 548-558.

90 A. C. Wallace, R. A. Laskowski and J. M. Thornton, Protein Eng., Des. Sel., 1995, 8, 127-134. 